\title{
Conciencia, condición y estado trágicos en el pensamiento de Albert Camus
}

\author{
María Teresa PADILLA LONGORIA \\ Universidad Nacional Autónoma de México
}

En este artículo nos proponemos mostrar que el punto de partida antropológico en el pensamiento de Albert Camus es el estatus trágico de los hombres, el cual implica el reconocimiento y la conciencia de nuestra condición y estado de seres mortales, limitados y sufrientes. Para exponer nuestro caso recurriremos a cinco de sus obras: El extranjero, en donde se muestra la impronta inmanente y autosuficiente del heroísmo de Meursault; El mito de Sísifo, como un canto al absurdo ante la ineluctabilidad victoriosa del destino trágico de los hombres; La peste, como crónica objetiva de guerra que enuncia la esencia contradictoria de la naturaleza humana, y El hombre rebelde y Las cartas a un amigo alemán, como testimonios de una rebeldía sin concesiones en cuanto lucha contra el absurdo inexorable de la vida humana. Haremos ver que la propuesta final de Camus alcanza su más alto refinamiento ético-estético como posible salvación antropológica en el binomio bondad-belleza arraigado a una búsqueda de justica telúrica.

PALABRAS ClaVE: A. Camus, absurdo, heroísmo, luz, sinsentido, rebeldía, destino, muerte, suicidio, sufrimiento, conciencia.

The aim of this paper is to show that the starting anthropological point in Albert Camus' thought is the tragic status of men which implies the recognition and the awareness of our condition and state of mortal, limited and suffering beings. To put forward our case we will resort to five of his works: The Stranger, in which is shown the immanent imprint and self-sufficient heroism in Meursault; The Myth of Sisyphus, as a song to the absurd before the victorious ineluctability of the tragic destiny of men; The Plague, as an objective war chronicler which states the contradictory essence of human nature, and The Rebel and Letters to a German Friend as testimonies of a rebelliousness with no concessions as for a struggle against the inexorable absurdity of human life. We will show that the final proposal in Camus reaches its highest ethical-aesthetic refinement as a possible anthropological salvation in the goodness-beauty binomial deeply rooted on a search of telluric justice.

KEY-WORDS: A. Camus, absurd, heroism, light, non-sense, rebelliousness, destiny, death, suicide, suffering, awareness. 


\section{Introducción}

No es meramente accidental el hecho de que Camus introduzca como epígrafe inicial de su obra El mito de Sísifo el épodo tercero de la Pítica III de Píndaro: Mí, pí $\lambda \alpha$

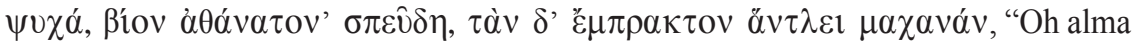
mía, no procures la vida inmortal, sino agota el campo de lo posible". ${ }^{1}$ Camus reconoce como punto de partida, al igual que los griegos, el estatus trágico de los hombres, a saber, nuestra condición y estado de seres mortales, limitados y sufrientes. Así como el heroísmo trágico griego se procuraba, en ocasiones, una especie de trascendencia, la cual implicaba el dar la vida o el morir joven para seguir siendo recordado eternamente, el heroísmo en Camus es inmanente y autosuficiente. ${ }^{2}$ Sin dejar de reconocer este destino inminente, ineluctable e implacable de nuestra condición humana y el absurdo que éste comporta, el oriundo de Argelia pensó — en contraposición con la condena a la desesperación de Sartre- que hay una buena lucha que busca y se vale de todos los recursos humanamente accesibles y se esfuerza por la realización de lo posible. La heroicidad de Camus no se atormenta ni se aferra a esperanzas ultramundanas, sino que se afianza a la vida por sí misma, a pesar de todas las miserias intramundanas:

Commencer à penser, c'est commencer d'être miné. La société n'a pas grand chose à voir dans ces débuts. Le ver se trouve au coeur de l'homme. C'est là qu' il faut le chercher. Ce jeu mortel que mène de la lucidité en face de l'existence à l'évasion hors de la lumière, il faut le suivre et le comprendre (Camus, Le mythe: 19). ${ }^{3}$

Empezar a pensar es como empezar a estar minado. La sociedad no tiene gran cosa que ver en estos comienzos. El gusano se encuentra en el corazón del hombre. Es allí en donde debemos buscarlo. Este juego mortal, que lleva de la lucidez de cara a la existencia a la evasión fuera de la luz, es necesario seguirlo y comprenderlo.

\section{El extranjero}

En primer lugar, nos percatamos, de este modo, de que la redención de Meursault es terrenal: él experimenta, poco antes de su ejecución y desde la ventana de la celda, una

${ }^{1}$ Pindar, Olympian Odes. Pythian Odes, pp. 250-251. Píndaro también alude al carácter efímero y fugaz

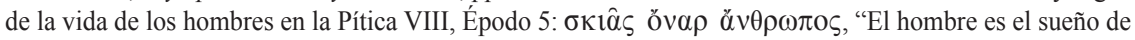
una sombra", ibid., pp. 336-337. En la tradición hebraica también se hace mención de la fragilidad y cortedad de la existencia humana frente a la omnipotencia y eternidad divinas, véase el Salmo 89 bíblico y, en particular, los versículos 5 a 6 , que dicen: "Te los llevas, no fueron más que un sueño, / son como flor de un día / que en la mañana brota y se ve verde / y en la tarde se marchita y se seca".

${ }^{2}$ En relación con el tema de la tragedia en Camus y el retorno a la fuente griega; a este respecto, así como el planteamiento de un renacimiento dramático en Occidente, véase su texto "Sur l'avenir de la tragédie", en Oeuvres complètes III 1949-1956, pp. 1117-1127.

${ }^{3}$ Véanse también pp. 22-23. Las traducciones del francés son propias. Agradezco a Édgar Meza las revisiones - y siempre atinadas sugerencias, observaciones y adiciones - que llevó a cabo de las mismas. 
especie de luz al "contemplar el cielo cargado de constelaciones y de estrellas". ${ }^{4} \mathrm{De}$ hecho, las referencias, alusiones y metáforas de la luz y lo luminoso y sus cognados son reiterativas en El extranjero y desempeñan un papel fundamental en las acciones de Meursault. ${ }^{5}$ Algunos han buscado y querido ver en el nombre mismo de Meursault un posible mensaje de Camus, pues parece que su onomatología nos remite al significado de una armonía de contrarios que son por ello complementarios: la raíz Meur que por cierta homofonía haría referencia a Mer (mar) y a il Meurt (él muere) y sault que remitiría a soleil (sol). Por consiguiente, si Meursault representa la condición humana esto significa que, no obstante la mar de posibilidades y la luz del sol, todos somos, indefectiblemente, seres finitos y mortales. Dicho en otros términos: la vida tiene su "derecho y su revés", y a pesar de su germen e impronta de absurdidad, vale la pena de ser vivida.

Meursault, una vez que es apresado, pasa a vivir de la indiferente cotidianidad como extranjero de sí mismo, al disfrute del proceso interior de la autognosis y al sentido profundo de la evocación de los más mínimos recuerdos. Así, desde el interior de su celda en prisión rememora:

Si bien qu'au bout de quelques semaines, je pouvais passer des heures, rien qu'à dénombrer ce qui se trouvait dans ma chambre. Ainsi, plus je réfléchissais et plus de choses méconnues et oubliées je sortais de ma mémoire. J'ai compris alors qu'un homme qui n'aurait vécu qu'un seul jour pourrait sans peine vivre cent ans dans une prison. Il aurait assez de souvenirs pour ne pas s'ennuyer. Dans un sens c'était un avantage (Camus, L'étranger: 116-117). ${ }^{6}$

De manera que al cabo de algunas semanas yo podía pasar las horas, tan sólo enumerando lo que se encontraba en mi recámara. Así, entre más reflexionaba, más cosas mal apreciadas y olvidadas me venían a la memoria. Entonces comprendí que un hombre que no hubiera vivido más que un solo día podría, sin pena, vivir cien años en una prisión. Tendría bastantes recuerdos para no aburrirse. En ese sentido, era una ventaja.

Meursault se halla en la encrucijada que entraña la confluencia — en términos del filósofo Eduardo Nicol— de los factores de la acción, a saber, el azar (que nos remite a la contingencia y a la oportunidad), el destino (que hace referencia a los dos binomios necesidad/posibilidad y determinación/limitación) y el carácter (que se expresa en términos de libertad e iniciativa), ${ }^{7}$ pues afirma durante el interrogatorio que fue por azar tanto el hecho de que él estuviera armado como el que se hallara en el lugar del

\footnotetext{
${ }^{4}$ Camus, L'étranger: 179: “devant cette nuit chargée de signes et d'étoiles".

${ }^{5}$ Véanse ibid., I, 1, p. 16; I, 3, p. 40; I, 6, pp. 77, 81, 86, 87, 89, 90; II, I, pp. 97-98, 100; II, 3, pp. 130131; II, 4, p. 150; II, 5, pp. 161, 172, 178-179.

${ }^{6}$ En relación con el proceso introspectivo y de autognosis de Meursault es claro cuando dice: “Et j'ai eu l'impression bizarre d'être regardé par moi-même", II, 3, p. 126.

${ }^{7}$ Véase Eduardo Nicol, Psicología de las situaciones vitales, cap. V, passim.
} 
incidente - lo cual es corroborado por el testimonio de Raymond. ${ }^{8}$ Pero, igualmente,

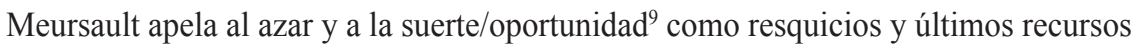
esperanzadores de salvación ante la mecánica implacable de la guillotina. Pronto se percata de la accidentalidad y, por ende, indeterminación e inconstancia de los mismos. No es fortuito que el protagonista de El extranjero haga toda una descripción minuciosa de la guillotina y repare en que la opinión común que tenía del artefacto como obra de precisión (précision), perfectamente acabada (fini) y centellante (étincelant) distaba mucho de la cruda realidad mostrada en su descarada simplicidad y efectividad mecánica que segaba todo: se estaba muerto "con un poco de vergüenza y mucha precisión". ${ }^{10}$

Es justamente a raíz de que Meursault es condenado a la pena capital y de la crudeza e imposibilidad de escapatoria que ellas implican que Camus pone en boca de su "héroe pagano"11 su condena a la pena de muerte. ${ }^{12}$ Así, Meursault empieza a reflexionar sobre sus proyectos de ley y sus reformas a los castigos y condenas:

J'avais remarqué que l'essentiel était de donner une chance au condamné. Une seule sur mille, cela suffisait pour arranger bien des choses. Ainsi, il me semblait qu'on pouvait trouver une combinaison chimique dont l'absorption tuerait le patient (je pensais: le patient) neuf fois sur dix. Lui le saurait: c'était la condition. Car en réfléchissant bien, en considérant les choses avec calme, je constatais que ce qui était défectueux avec le couperet, c'est qu'il n'y avait aucune chance, absolument aucune. Une fois pour toutes, en somme, la mort du patient avait été décidée. C'était une affaire classée, une combinaison bien arrêtée, un accord entendu et sur lequel il n'était pas question de revenir (Camus, L'étranger: 62).

Me había percatado de que lo esencial era darle una oportunidad al condenado. Sólo una entre mil, eso bastaba para arreglar muchas cosas. De esta manera, me parecía que se podía encontrar una combinación química cuya absorción mataría al paciente (yo pensaba: el paciente) nueve de diez veces. Él lo sabría: era la condición. Puesto que, pensándolo bien, y considerando las cosas con calma, yo constataba que lo que estaba defectuoso con la cuchilla, es que no había ninguna oportunidad, absolutamente ninguna. De una vez por todas, en suma, la muerte del paciente había sido decidida. Era un asunto cerrado, una combinación bien determinada, un acuerdo sobrentendido y sobre el cual no había vuelta de hoja.

\footnotetext{
${ }^{8}$ Camus, L'étranger, II, 3, pp. 130, 140, II, 4, p. 159.

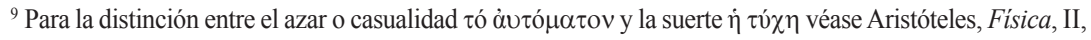
5 y 6 , passim.

${ }^{10}$ Camus, L'étranger, II, 5, p. 164: "on était tué discrètement, avec un peu de honte et beaucoup de précision".

${ }^{11}$ Parafraseando el título de Robert Champigny, Sur un héros païen.

${ }^{12}$ En relación con las consideraciones de Camus en torno al tema de la pena capital, véanse Reflexiones sobre la guillotina, en La pena de muerte en colaboración con Arthur Koestler, trad. M. Peyrou, introducción de J. Bloch-Michel, Buenos Aires, Emecé Editores, 1960-2003, pp. 111-165.
} 
La posición de Meursault es radical y sin ambages de ninguna índole. De forma que en el diálogo final con el capellán rechaza todo tipo de esperanza religiosa, ultramundana o transmundana. Sabe que morirá por completo ("tout entier") (Camus, L'étranger: 171-172) y que no representa ningún tipo de consuelo para un sentenciado a la pena capital la fría aseveración, a manera de conclusión silogística, que todos los hombres somos mortales. ${ }^{13}$ Indudablemente, Camus tenía cultura religiosa, porque este desprecio que se conoce, en términos de la teología católica, como impenitencia final de Meursault a toda intercesión o intermediación divina es contundente, pues implica un pecado contra el Espíritu Santo — que son de los que no se perdonan-, el cual consiste en que con vistas a la muerte se rechace el último llamado a la Gracia de Dios y al arrepentimiento del mal que se hubiera podido cometer. ${ }^{14}$ Meursault no acepta, siquiera, que el capellán le hable en términos de pecado ni de Dios. Para el protagonista de El extranjero si hay redención o algún tipo de felicidad y, más aún, de justificación y seguridades vitales, éstas son completamente telúricas (Camus, L'étranger: 172-179).

\section{El mito de Sisifo}

En segundo término, Camus nombra a Sísifo el héroe del absurdo por antonomasia (Camus, Le mythe: 164). Desde el principio de su obra El mito de Sísifo. Un ensayo sobre el absurdo nos encara sin sutilezas de ninguna índole con el problema filosófico fundamental e insoslayable: el suicidio y, con ello, si la vida vale o no la pena de ser vivida (Camus, Le mythe: $17 \mathrm{y}$ ss). Plantearse la pregunta más acuciante, es decir, por el sentido de la vida, comporta, a su vez, un doble despliegue de problemas: aquellos que son causantes de muerte - o nos ponen en riesgo de morir - o los que multiplican la pasión por vivir. Ambos habrán de ser abordados por un sujeto dotado de humildad y patetismo de forma que le permita asumir una actitud de auténtica modestia procedente tanto del sentido común como de la simpatía. ${ }^{15}$

\footnotetext{
${ }^{13}$ Véase en lo referente al tema de la condena a muerte por algún tipo de desahucio, llámese legal o médico, D. Buzzati, el relato "Equivalenza", en Le notti difficili, pp. 17-20.

${ }^{14} \mathrm{El}$ Catecismo de la Iglesia católica (p. 426) afirma: “"El que blasfeme contra el Espíritu Santo no tendrá perdón nunca, antes bien será reo de pecado eterno' (Mc 3, 29; Mt 12, 32; Lc 12, 10). No hay límites a la misericordia de Dios, pero quien se niega deliberadamente a acoger la misericordia de Dios mediante el arrepentimiento, rechaza el perdón de sus pecados y la salvación ofrecida por el Espíritu Santo ( $c f$. De V 46). Semejante endurecimiento puede conducir a la condenación final y la perdición eterna". Los otros dos pecados contra el Espíritu Santo son: la obstinación en los pecados y la retención del salario de los pobres. También recordemos que, por motivos de salud, Camus nunca logra obtener la agregaduría para la que había concursado, pero, para ello, presentó un trabajo (Diplôme d'études supérieures) sobre Plotino y san Agustín titulado Métaphysique chrétienne et neoplatonisme, que obtuvo, simplemente, la mención de "Bien" ante un jurado compuesto por René Poirier, Jean Grenier y Louis Gernet.

${ }^{15}$ Ésta es la razón por la cual Camus coloca como prototipos del pensamiento a Don Quijote y a La Palisse a fin de lograr el equilibrio entre el lirismo y la evidencia (Le mythe: 18).
} 
Sísifo concentra, a juicio de Camus, ese pathos que se traduce, en forma activa, en una pasión tal por la vida que lo lleva a despreciar a los dioses y a odiar a la muerte y, en forma reactiva, a sufrir y padecer los tormentos más indecibles, producto de su actitud frente a las divinidades, frente a la tierra y frente a la muerte.

Camus hace una disección de lo más refinada del suplicio interminable de Sísifo. Por un lado, resalta la vacuidad espacio-temporal, la ausencia de perspectiva y el carácter inútil y siempre inacabado del esfuerzo, del sufrimiento, de la ocupación, del desgaste y consunción del héroe pegado a una roca. Por otro, distingue la seguridad totalmente humana de Sísifo en el momento de su descenso de la cúspide a la llanura, el remanso de la conciencia del hombre-piedra que respira y transpira su desdicha. Es en estos instantes en donde Sísifo es superior a su destino y a su escollo. Por consiguiente, la esencia trágica del mito de Sísifo reside en la doble conciencia del héroe: la inexorabilidad de su tormento lo consolida en la superación victoriosa de su destino. Es precisamente aquí en donde se da la intersección entre la sabiduría antigua y el heroísmo moderno: como conciencia trágica en el Edipo de Sófocles y en el Kirilov de Dostoyevski, de forma que el Sísifo consciente asume, hace suyo y hereda su destino pedregoso como un cántico puramente humano y entre los hombres al absurdo, absurdo que es límite de lo posible, pero al fin y al cabo posibilidad. Así, el hombre, todo hombre, arroja los dados para iniciar el juego con su destino. Contra lo illacrimabilis (lo que no se deja vencer por las lágrimas), lo inexorabilis (lo que no se deja vencer por los ruegos) y lo implacabilis (lo que no se deja aplacar), Sísifo responde con su alegría afirmativa e incesante esfuerzo que lo hacen dueño y señor de su tierra y de cada fragmento de su roca siempre rodante. La noche eterna de Edipo cegado no es impedimento para que, junto con Sísifo, sigan luchando por desear ver (Camus, Le mythe: 164-168). Así cierra Camus su loa al absurdo:

Je laisse Sisyphe au bas de la montagne! On retrouve toujours son fardeau. Mais Sisyphe enseigne la fidélité supérieure qui nie les dieux et soulève les rochers. Lui aussi juge que tout est bien. ${ }^{16}$ Cet univers désormais sans maître ne lui paraît ni stérile ni futile. Chacun des grains de cette pierre, chaque éclat minéral de cette montagne pleine de nuit, à lui seul forme un monde. La lutte elle-même vers les sommets suffit à remplir un coeur d'homme. Il faut imaginer Sisyphe heureux (Camus, Le mythe: 168).

¡Dejo a Sísifo al pie de la montaña! Uno se encuentra siempre con su fardo. Pero Sísifo enseña la fidelidad superior que niega a los dioses y eleva las rocas. Él también juzga que todo está bien. Desde ahora este universo sin amo no le parece ni estéril ni fútil. Cada uno de los granos de esta piedra, cada destello mineral de esta montaña colmada de noche constituye, por sí solo, un mundo. La lucha misma hacia las cúspides basta para satisfacer un corazón humano. Es necesario imaginar un Sísifo feliz.

\footnotetext{
${ }^{16}$ Tal y como Camus lo había aseverado en relación con Edipo: "Malgré tant d'épreuves, mon âge avancé et la grandeur de mon âme me font juger que tout est bien" (Le mythe: 166).
} 


\section{La peste}

La tercera instancia para presentar el absurdo como narración "objetiva", y a manera de antropología filosófica, la constituye su crónica de guerra, La peste. Aquí Camus nos encara con la pregunta qué es el hombre. ${ }^{17}$ El médico, Bernard Rieux, es el ojo avizor que inquiere, a través de las diversas manifestaciones de la pandemia, en la médula de la condición humana. Rieux, en diálogo con Tarrou, afirma que dado que el orden del mundo está regulado por la muerte, es mejor no creer ni levantar los ojos al cielo hacia un Dios silente, sino luchar con todas las propias fuerzas contra la muerte, aunque las victorias sean meramente provisionales $\mathrm{y}$, por ende, la derrota interminable (Camus, La peste: 130-131).

El carácter omnímodo de la peste en Orán hace que sus habitantes se vuelvan prisioneros del tiempo en un sufrimiento inextinguible: constreñidos a un pasado reducido a la nostalgia e irreconciliable con un presente generador de impaciencia y cercenador del porvenir. La plaga aniquilaba la memoria, la esperanza y toda posibilidad de elección o de relación afectuosa: la sucesión de meros instantes impedía, así, cualquier proyección de vida (Camus, La peste: 256). ${ }^{18}$

Pero Camus no reduce su idea del hombre a la pura negatividad, pues también es capaz de poner, en boca del mismo Tarrou, la aseveración de que cuando él contempla los ojos de la madre de Rieux, y al poder leer en ellos tanta bondad, ésta será siempre más fuerte que la peste (Camus, La peste: 119).

Otro de los grandes cuestionamientos con el cual Camus nos encara en La peste es el del sufrimiento y agonía de los inocentes. De nueva cuenta es el doctor Rieux quien hace explícita la idea medular al respecto, a saber, que el gran escándalo, en concreto, generado por la plaga devastadora en Orán es el dolor, la tortura y la muerte infligidos a sus niños. ${ }^{19}$ Por eso el médico acaba concluyendo que él no tiene afinidad alguna ni con el heroísmo ni con la santidad y que lo que simplemente le interesa es ser hombre (Camus, La peste: 253).

La pandemia era susceptible de ser contenida tan sólo en la medida en que la más recóndita esperanza se hacía posible y ésta era abrigada entre los conciudadanos, aunque fuese en su matiz más sutil (Camus, La peste: 270-271). Pero la peste siempre se afanaba en ser sorpresiva, de manera que continuaba despistando a todos y se enraizaba donde no se la esperaba y se difuminaba allí donde se la creía arraigada (Camus, $L a$ peste: 284). Rieux sabía que después de la vivencia de la peste la derrota se vuelve

\footnotetext{
${ }^{17}$ Tal y como asevera Philippe Delaroche: “Camus n'a jamais perdu de vue l'extraordinaire complexité de l'être humain", en P. Delaroche et al., "Camus telquel (Dossier)", Lire, 420, nov., 2013, p. 26.

${ }^{18}$ Véanse Camus, La peste: 75-77; III, pp. 183-184, IV, p. 256.

${ }^{19}$ Véase Camus, La peste: IV, pp. 213, 217; 224-227, 259. Asimismo, en estos pasajes, Camus hace explícita la forma en la cual el cristianismo busca darle un sentido — mas no una justificación — al sufrimiento de los inocentes en su personaje, Paneloux, el sacerdote.
} 
permanente porque, aunque se ponga fin a una guerra, la paz ya sólo podrá ser asumida desahuciadamente, como un dolor sin esperanza alguna de cura. El triunfo parcial ante la plaga se concentraba en el juego de la memoria sin ilusión: el recuerdo y el conocimiento (Camus, La peste: 290-299).

La peste nos enseña, por consiguiente, que a pesar de todo el cúmulo de violencia, de maldad, de miseria y podredumbre, también hay solidaridad, hay ternura y, más aún, bondad humanas, porque, colige Camus:

[...] qu'il y a dans les hommes plus de choses à admirer que de choses à mépriser (Camus, La peste: 308 ).

[...] en los hombres hay más cosas dignas de admiración que de desprecio.

\section{El hombre rebelde y Cartas a un amigo alemán}

El cuarto recurso contra el absurdo omnímodo es la rebeldía. Ésta toma un cariz muy particular y refinado en Camus, pues no se permite concesiones de ninguna especie: la crítica y el ejercicio de la libertad no han de perder su inocencia y, por ende, autenticidad, cediendo a las tentaciones de cualquier forma de absolutismo - ya sea político, moral o religioso. ${ }^{20}$

La generosidad del hombre rebelde es completa y fecunda, pues da su fuerza amorosa sin dilaciones y repudia cualquier forma de injusticia. Su honor es terrenal, ya que su dinamismo reside en la vida misma al no escatimar nada y repartir todo en esta vida a sus hermanos vivientes. Así es como se prepara un renacimiento que vaya más allá del nihilismo (Camus, El hombre: $375-379){ }^{21}$

J'ai choisi la justice au contraire, pour rester fidèle à la terre. Je continue à croire que ce monde n'a pas de sens supérieur. Mais je sais que quelque chose en lui a du sens et c'est l'homme, parce qu'il es le seul être à exiger d'en avoir. Ce monde a du moins la vérité de l'homme et notre tâche est de lui donner ses raisons contre le destin luimême. Et il n'a pas d'autres raisons que l'homme et c'est celui-ci qui'il faut sauver si l'on veut sauver l'idée qu'on se fait de la vie. Votre sourire et votre dédain me diront: qu'est-ce que sauver l'homme? Mais je vous le crie de tout moi-même, c'est ne

\footnotetext{
${ }^{20}$ Muy alusivas al tema son las palabras que Camus dijo en "El pan y la libertad", en Ensayos, Actualidades II, Creación y libertad, p. 428: "Si la libertad está hoy humillada o encadenada, no lo es porque sus enemigos han usado de la traición. Es porque, precisamente, ha perdido su protector natural. Sí, la libertad está viuda, pero hay que decirlo, porque es cierto: está viuda de todos nosotros".

${ }^{21}$ Asimismo, Camus introduce como uno de los epígrafes de su obra Lettres à un ami allemand (65) las palabras que Étienne de Senacour pone en boca de su héroe Obermann en su novela epistolar epónima: "L’homme est périssable. Il se peut; mais périssons en résistant, et si le néant nous est réservé, ne faisons pas que ce soit une justice!” "El hombre es perecedero. ¡Es posible; pero perezcamos resistiendo, y si la nada nos está reservada, no hagamos de eso un acto de justicia!”
} 
pas le mutiler et c'est donner ses chances à la justice qui'il est le seul à concevoir (Camus, Lettres: 71-72).

Por el contrario, escogí la justicia, para permanecer fiel a la tierra. Sigo pensando que este mundo no tiene un sentido superior. Pero sé que alguna cosa en él tiene sentido y eso es el hombre, porque él es el único ser que exige que lo tenga. Este mundo tiene, al menos, la verdad del hombre y nuestra tarea consiste en darle sus razones contra el destino mismo. Y no hay otras razones más que el hombre y es éste al que es necesario salvar si se quiere salvar la idea que se tiene de la vida. Su sonrisa y su desdén me dirán: ¿qué es salvar al hombre? Pero yo se lo pregono con todo mi ser, no implica mutilarlo, sino dar[le] sus oportunidades a la justicia, pues él es el único capaz de concebirla.

El heroísmo trágico de Camus adquiere entonces su cariz más refinado y, por ende, su auténtica conformación ético-estética. Si hay salvación ésta será vía el binomio bondad-belleza que el hombre busque infatigablemente como sentido de justicia con vistas a permanecer fiel a la tierra.

Valgan estas Jornadas en homenaje a Albert Camus para recordarnos lo que significó la autenticidad, es decir, vivir pensando o vivir en conformidad con lo que se pensó al hacer de la reflexión activa o de la actividad reflexiva una forma de vida.

\section{Obras citadas y de consulta}

BuZzATI, Dino. Le notti difficili. Milán: Oscar Mondadori. Ristampa, 2012. Impreso. CAmus, Albert. Ni víctimas ni verdugos. Buenos Aires: Ediciones Godot, 2014. Impreso.

. "Sur l'avenir de la tragédie", en Oeuvres complètes III 1949-1956. Edición publicada bajo la dirección de R. GAY-CrOISIER et al. París: Gallimard, 2008. Impreso.

. Lettres à un ami allemand. Barcelona: Gallimard, 2007. Impreso.

. Le mythe de Sisyphe. Essai sur l'absurd. París: Gallimard. 1942-2003. Impreso.

. Reflexiones sobre la guillotina en La pena de muerte, en colaboración con

A. Koestler. Trad. M. Peyrou. Introd. J. Bloch-Michel. Buenos Aires:

Emecé Editores, 1960-2003. Impreso.

La chute. Saint-Amand: Gallimard, 2002. Impreso.

. El hombre rebelde. Trad. L. ECHÁvarri. Buenos Aires: Alianza/Losada, 1982. Impreso.

. Calígula. Trad. A. Bernárdez. Madrid: Losada, 1981. Impreso.

Ensayos, Anverso y reverso. Bodas. El mito de Sísifo, Cartas a un amigo alemán, Actualidades I, II y III, El hombre rebelde, El verano, "Carnets" I y II, Discurso de Suecia. Trad. J. LAGo. Aguilar: Madrid, 1981. Impreso. 
Les justes. Saint-Amand: Gallimard, 1978. Impreso.

La peste. Saint-Amand: Gallimard, 1975. Impreso.

El extranjero. Trad. B. DEL CARRIL. Barcelona: Planeta, 1970. Impreso.

El mito de Sisifo. El hombre rebelde. 6a. ed. Trad. L. ECHÁvARRI. Madrid

/ Buenos Aires: Alianza / Losada, 1970. Impreso.

. El revés y el derecho. 3a. ed. Trad. A. L. Bixio. Buenos Aires: Losada,

1968. Impreso.

L'étranger. París: Gallimard, 1957. Impreso.

La caída. México: Zarco, 1956. Impreso.

La muerte feliz. Trad. J. GomIs. Barcelona: Noguer. [s. a.]. Impreso.

La peste. Trad. R. Chacel. México: Azteca, [s. a.]. Impreso.

Catecismo de la Iglesia católica. Buenos Aires: Lumen, 2014. Impreso.

CHAMPIGNY, Robert. Sur un héros païen, Les Essais, XCIII; NRF. París: Gallimard, 1959. Impreso.

Delaroche, Phillippe et al. "Camus telquel (Dossier)", Lire, 420. Nov., 2013. Pp. 26-51.

EAST, Bernard. Albert Camus ou l'homme à la recherche d'une morale. Montreal / París: Bellarmin / CERF, 1984. Impreso.

Moeller, Charles. Literatura del siglo XX y cristianismo. Volumen I: El silencio de Dios. Camus, Gide, A. Huxley, Simone Weil, Graham Greene, Julien Green, Bernanos. Trad. V. GARCía YeBra. Madrid: Gredos, 1970. Impreso.

Nicol, Eduardo. Psicología de las situaciones vitales. 2a. ed. corregida. México: FCE, 1963.

O’Brien, Conor, C. Camus. Trad. A. Roies. Barcelona / México: Grijalbo, 1973. Impreso.

PÉreZ, Ana Rosa y Antonio Zirión. La muerte en el pensamiento de Albert Camus. México: UNAM, 1981. Impreso.

Pindar, Olympian Odes. Pythian Odes. Ed. y trad. W. H. RaCe. Cambridge, Massachussetts / Londres: Harvard University Press, 1997. Impreso.

Salomon, P. Guides Bordas, Concours-Examens-Formation. Littérature Française, Les mouvements Littéraires, Les Écrivains-Leurs Oeuvres. París, Bordas, 1978. Impreso.

SASA, Ghada S. y Malek K. BenlahCENE, "When individuality becomes a plight in Richard Wright's Black Boy and Albert Camus' The Stranger". Canadian Social Science, vol. 7, núm. 3, 2011. Pp. 27-34. Impreso.

SCHERR, Arthur. Winter. "Meursault's dinner with Raymond: a Christian theme in Albert Camus's L'Étranger". Christianity and Literature, vol. 58, núm. 2, 2009. Pp. 187-210. Impreso. 